\title{
A Look at Readers in the UAE and the Factors that Influence Them
}

\author{
Afra Atiq Juma \\ Mass Communication Dept, Humanities and Social sciences college, UAE \\ *Corresponding Author: Afra Atiq Juma, Mass Communication Dept, Humanities and Social \\ Sciences College, UAE
}

Received Date: 07-07-2017

Accepted Date: 15-07-2017

Published Date: 28-07-2017

\begin{abstract}
It is clear that reading is an essential life skill. So essential, in fact that, reading can be asserted as the key to "personal development, and to social, economic and civic life", (Holden 2004, cited in Clark and Kate Rumbold, 2006). Reading provides a learning platform for personal and professional growth. Manguel (1996) equates reading with breathing and labels it an "essential function." Several scientific studies have revealed the benefits of reading. Wilson et al. (2013) found that reading was shown to decrease memory decline in the elderly in a group of 294 participants and the rate of memory decline participants who did not read was 48 percent faster. Similarly, Bower (2013) linked reading to reducing depression. In addition, Bal and Veltkamp (2013) concluded that reading fiction increases a person's empathy. According to Holt (1998) a society in which a large number of people do not actively read can have dire consequences for the future development of that society. He points out that the reasons behind a lack of reading lies in people not willing to take the time to read because they have not been taught to take pleasure in reading. Sisulu (2004) and Gobert (2016) both assert that reading is the basic foundation of learning - without it students will be unable to learn and reach their full potential. Yet despite the numerous, and documented, benefits of reading, there is growing concern about a general decline of reading among the youth. Akanda, Gausul Hoq and Hasan (2013) contend that "the reasons of the decline in the reading habits of the general public, especially students and young people, are being widely debated and discussed by academicians, intellectuals, writers, librarians, and reading enthusiasts."
\end{abstract}

Keywords: Readers in the UAE, reading culture, society, Purpose and context.

\section{DEFINING READING}

Though the exact definition of what constitutes reading varies from scholar to scholar and country to country, it can be agreed the that the process of reading is a set of complex cognitive functions. In fact, as Abu Shihab (2011) points out, the act of reading is so complex that it spans the fields of psychology, linguistics and sociology. He refers to Anderson and Pearson (1984) to illustrate that reading is the acquisition of new information as compared to old information already possessed by the reader. This is contrasted, by Abu Shihab (2011) through sentiments that echo Wittgenstein's language and universe limitations standpoint. against a citation of Goodman (1976) which asserts that reading is a "psycholinguistic guessing game" that is at the intersection of both thought and language. However, Palani (2012) states that reading requires the reader to bring prior experiences and thoughts in order to understand a text, rather than interpreting words from text only.

\section{Developing a Reading Culture/ SOCIETY}

When discussing building a reading society, or culture, it is important to distinguish between reading habits and literacy. Literacy, as Etim (2008) points out, the latter, refers to literacy as "an individual's ability to read, write and speak in English." (cited in Igwe 2011). Where as a reading habit is using reading as a regular activity and is fundamental to student success (Nssien, 2008 cited in Igwe 2011). It is pertinent to, first, define the complex concept of culture before defining a reading culture. When defining culture, Ruterana (2011) quotes Vygotsky (1993) as defining culture as "the product of man's social life and his public 
activity." He goes on to postulate a reading culture, by Vygotsky's definition is a society in which people utilize reading as a means to conduct their daily lives. Magara and Batambuze (2005 cited in Stranger-Johannessen 2014). In addition, (Stranger-Johannessen 2014) contents that, based on previous studies, "developing a reading culture is not just about quantity of reading." It is agreed upon that the key to sustainable reading culture lies in a person's motivation to read, just as Mansor et al. (2012) concluded. Scholars agree that, although there is no single way to measure reading as a single entity, a reading society can be measured by the number of avid, or active, readers.

In line with Palani's (2012) identification of factors that contribute to avid reading, Mansor et al. (2012) took the idea a few step further through quantitative research focusing on the major areas of home and school. To that end, Mansor et al. (2012) points out that development of healthy reading habits, which lead to avid reading, begin during childhood. He identifies that children which an active interest come from "supportive literary environments at home." $\mathrm{He}$ asserted that children with a high interest in reading came from parents that support the literary environments at home (ibid). In Mansor's study, they used a cross-sectional survey with two mixed-gender target groups and profiled the habitual reader in order to identify differences in impacting factors. This follows the habitual reader profile identified by Pandian (2000) through the Explanatory Model of Reading Behavior.

The results of Mansor et al (2012) finds that reading beings at home during childhood and is carried on, almost dependently, through the community. A significant finding also points to parental involvement, and a need to stay motivated by those outside the home.



Fig1. Pandian's Explanatory model of reading behaviour

\section{Purpose and Context}

The government of the United Arab Emirates declared 2016 be the Year of Reading. This declaration was not a one-off initiative, but it was part of a boarder framework and long term strategy to create a well-read society. To this end, the UAE unveiled 10-year plan underscored by a new reading law. The reading law and 10year plan are part of the crucial development of the society of the UAE. Since the dramatic publication of the amount Arab children read which states that average Arab child reads just an average of six minutes a year (Cited in Khaleej Times, 2015). Roughly, this translates to 30 seconds per month which is enough to alarm even the most well-read societies.
Therefore, it is pertinent to look into understanding the reading culture of Emiratis and residents in the UAE as well as the factors that impact it. For the purpose of this research, it is necessary to expand on the Explanatory Model of Reading Behavior.

This study attempts to answer three research questions as follows:

R1) Is there an active reading culture in the UAE among citizens and residents? How much to they read?

R2) Is there a relationship between being an active reader and amount and variety of books: at home and in the classroom?

R3) Is there a relationship between external 
encouragement (parent), and general community) and being an active reader?

\section{METHODOLOGY}

This study looks at the relationships between self-identified active readers, amount and variety of reading materials available (in homes and schools), and external motivation (in homes and the community). It is based on a dataset of a total of 200 people who participated in the study, this included both Emirati citizens and expatriate residents of the country. The study is quantitative in nature and identifies the factors impacting reading habits of people in the United Arab Emirates in three major areas of focus. These areas are the home, the school and the community. This was conducted using a random sample of general population of the UAE. The model framework for this study (shown in Fig 2) is adapted based on the work of Mansor (2012), Palani (2012) and Pandian (2000) used as a base for the questions asked for data collection. It mainly focuses on the factors that impact reading habits, as well as, the highlighting the importance of external motivation.



Fig2.

The survey method was implemented for this study to collect the data. An electronic survey composed of 37 questions was distributed to the participants via Twitter.

All participants completed a minimum of high school and were between the ages of 16 and 58 . The pool of participants was made up of both males and females. It is noteworthy to state that the more than half of the participants were UAE citizens. The highest number of responses identified as being residents of Dubai, Abu Dhabi, and Sharjah at $45.2 \%, 28.1 \%$, and $15.1 \%$ respectively.

\section{Data Collection and Measurement}

For the measure of responses, the questions of the survey fall into two main categories: Openended and multiple choice on a Likert scale. Participants were asked to answer simple questions about reading habits in the three areas of home, school and community.

The survey was divided into five sections:

1. General reading habits

2. Reading habits at home

3. Reading habits at school

4. Reading Habits in the community

5. Background demographics

In the first section, participants were asked to identify how much of an active reader they are as well as the daily and weekly frequency with which they read. They were also how often they purchase reading materials and the frequency, preferred language, favorite medium, and location for reading. The second section asked the participants to rank the motivation by their guardians and siblings to read at home. In addition to the amount and variety of reading materials that were available to them in their houses. Finally, participants were asked to disclose their guardians highest level of education. The third and fourth sections revolve around variety, amount, and accessibility to reading materials and facilities. Also, these sections rank external encouragement to utilize these facilities. The fifth, and final, section collects background demographics on the participants and asks for their thoughts on the reading culture of the UAE.

\section{Data Analysis}

The data analysis was conducted using SPSS, focusing on cross tabulation, and the chi-square test to see the link between variables.

\section{RESULTS}

R1) Is there an active reading culture in the UAE among citizens and residents? How much to they read?

Table 1 shows a more accurate the distribution of participants' location, and how active of a reader they consider themselves to be. 
Table1.

\begin{tabular}{|c|c|c|c|c|c|c|c|c|c|c|c|}
\hline \multicolumn{12}{|c|}{ Do you consider yourself an active reader? "Which Emirate do you live in? Crosstabulation } \\
\hline \multicolumn{12}{|l|}{ ount } \\
\hline & & \multicolumn{9}{|c|}{ Which Emirate do you live in? } & \multirow[b]{2}{*}{ Total } \\
\hline & & & Abu Dhabi & Ajman & Dubai & Fujairah & $\begin{array}{c}\text { Ras Al } \\
\text { Khaimah }\end{array}$ & Response & Sharjah & $\begin{array}{l}\text { Umm Al } \\
\text { Quwain }\end{array}$ & \\
\hline \multirow{6}{*}{$\begin{array}{l}\text { Do you consider } \\
\text { yourself an active } \\
\text { reader? }\end{array}$} & Fairly active & 2 & 11 & 3 & 24 & 1 & 1 & 0 & 7 & 0 & 49 \\
\hline & Medium & 1 & 14 & 1 & 23 & 0 & 0 & 0 & 6 & 1 & 46 \\
\hline & Not active & 0 & 4 & 1 & 14 & 1 & 1 & 0 & 6 & 0 & 27 \\
\hline & Response & 0 & 0 & 0 & 0 & 0 & 0 & 1 & 0 & 0 & 1 \\
\hline & Somewhat active & 1 & 21 & 1 & 19 & 0 & 4 & 0 & 9 & 2 & 57 \\
\hline & Very active & 0 & 6 & 0 & 10 & 0 & 1 & 0 & 2 & 0 & 19 \\
\hline Total & & 4 & 56 & 6 & 90 & 2 & 7 & 1 & 30 & 3 & 199 \\
\hline
\end{tabular}

In terms of the sample of participants whose responses were collected for this study, the highest number of responses identified as being residents of Dubai, Abu Dhabi, and Sharjah at $45.2 \%, 28.1 \%$, and $15.1 \%$ respectively. Although this sample is relatively small, compared to the general population, it indicates that most participants identify themselves as fairly active, medium, and not active. Very active readers only account for almost $10 \%$ of the total number participants. While the highest number of participants, 57, consider themselves to be somewhat active readers, 49 participants claimed to be fairly active, 46 said they were medium, and 27 were not active at all.

Participants who considered themselves to be active readers identify as reading more 3 or more hours per day, outside assigned readings. On the flipside, those who identified as not being active readers read " 0 hours" per day outside of assigned reading. R2) Is there a relationship between being an active reader and amount and variety of books: at home and in the classroom?

In answer to R2, it cross tabulation and the chisquare test reveal that child exposure to books during childhood, for this sample of participants, interesting information. First it must be clarified that the assigned values to the variable labeled do you consider yourself an "Active reader", which will be used throughout this study, is ranked with the following values:

1. Not active

2. Somewhat active

3. Medium

4. Fairly active

5. Very active

It must also be pointed out that active readers are those who have developed healthy reading habits and not active readers have not.
Most (26.5\%) of "fairly active" readers had either between 100-200 as children, compared to most $(23.9 \%)$ "medium" readers who had less than 50 books at home. Notably, the category with the most participants (57 in total) identified themselves as was "somewhat active." An equal number of respondents, within the 57 total, reported $24.6 \%$ exposure to $100-200$ books in their households. Likewise, another $24.6 \%$ also reported exposure to 50-100 books in the home. Self-identified "very active" readers were $15.8 \%, 21.1 \%$, and $26.3 \%$ exposed to $100-200$, 50-100, and more than 500 books respectively.

When the chi-square test was applied to these values, it gave a $p$-value of $0.165, p>0.05$. This concludes that there is not a significant relationship between the number of books at home and the probability of becoming an active reader later in life.

There are two main takeaways from looking at the variety of books children are exposed to at home, rather than the sheer amount. The first is that and those are that there is a positive relationship between the variety of books in the home and "active readers" and also that there is negative relationship between the "not active" readers and the variety of books they have at home. As the highest number $(41 \%)$ of active readers have been exposed to a very varied collection of books at home during childhood and $21.1 \%$ had a "fairly varied" and "varied" types of books at home, respectively. What is interesting here, is that comparatively, the self identified $44.4 \%$ and $25.9 \%$ of "not active" readers did have access to a "somewhat varied" and "fairly varied" variety of books, respectively, as children. A chi-square test to see the relationship between whether the participants consider themselves to be active readers and the variety of books in the household, puts the pvalue at 0.13 , meaning that $p<0.05$ and there is a statistically significant relationship with the variety of books in the home. 


Chi-Square Tests
\begin{tabular}{|l|r|r|r|}
\hline & \multicolumn{1}{|c|}{ Value } & \multicolumn{1}{c|}{ df } & $\begin{array}{c}\text { Asymptotic } \\
\text { Significance } \\
\text { (2-sided) }\end{array}$ \\
\hline Pearson Chi-Square & $31.086^{\mathrm{a}}$ & 16 & .013 \\
Likelihood Ratio & 33.333 & 16 & .007 \\
Linear-by-Linear & 6.457 & 1 & .011 \\
Association & 198 & & \\
N of Valid Cases & & \\
\hline
\end{tabular}

For the classroom, participants were asked to state the amount of books they had in their classrooms (the options ranged from less than $25,25-50,50-75,75-100,100-125,125-$ 150 , and more than 150 books). These options were also assigned the values of $1,2,3,4,5,6$, 7 , respectively

Chi-Square Tests
\begin{tabular}{|l|r|r|r|}
\hline \multicolumn{1}{|c|}{} & \multicolumn{1}{c|}{ Value } & \multicolumn{1}{c|}{ df } & $\begin{array}{c}\text { Asymptotic } \\
\text { Significance } \\
\text { (2-sided) }\end{array}$ \\
\hline Pearson Chi-Square & $28.067^{\mathrm{a}}$ & 24 & .257 \\
Likelihood Ratio & 26.746 & 24 & .316 \\
Linear-by-Linear & .723 & 1 & .395 \\
Association & 198 & & \\
$\mathrm{~N}$ of Valid Cases & & \\
\hline
\end{tabular}

Cross tabulating, in a chi-square, the participant's answers and how they identify themselves as readers shows that the p-value is 0.257 and therefore $p>0.05$. There is not a statistically significant relationship between the two variables.

In terms of variety of reading material, the participants were asked to rank the variety of books available to them in their classroom (the options ranged from Not varied at all, somewhat varied, fairly varied, varied, and very varied). These options were also assigned weights from 1 to 5 , respectively. When conducting a chi-square test it is noticed that, unlike variety in the home, $p$-value is 0.447 . This means that $p>0.05$ and there is not a significant relationship between the two.

\begin{tabular}{|c|c|c|c|}
\hline \multicolumn{4}{|c|}{ Chi-Square Tests } \\
\hline & Value & df & $\begin{array}{c}\text { Asymptotic } \\
\text { Significance } \\
\text { (2-sided) }\end{array}$ \\
\hline Pearson Chi-Square & $16.091^{\mathrm{a}}$ & 16 & .447 \\
\hline Likelihood Ratio & 13.791 & 16 & .614 \\
\hline $\begin{array}{l}\text { Linear-by-Linear } \\
\text { Association }\end{array}$ & 2.935 & 1 & .087 \\
\hline $\mathrm{N}$ of Valid Cases & 198 & & \\
\hline
\end{tabular}

R3) Is there a relationship between external encouragement (parent), and (general community) and being an active reader?

To evaluate the relationship that external encouragement has with the likelihood of someone becoming an active reader or not, both the categories of those who identified themselves as "active readers" and "not active readers" were isolated from the rest of the rankings within the "do you consider yourself an active reader" variable. Therefore, this section will discuss only "active" and "not active" readers in the context of external encouragement in the home, school, and community. The results of cross tabulation are as follows: In terms of encouragement at home it should be noted that the values assigned to parental and sibling encouragement are as follows:

1- Not at all encouraged

2- Barely encouraged

3- Somewhat encouraged

4- Fairly encouraged

5- Very encouraged

A total of $55.6 \%$ of self-identified "not active readers" reported being "barely encouraged to read by parents/guardians. Further $22.2 \%$ and $11.1 \%$ said they were "somewhat encouraged to read" and "fairly encouraged to read", respectively. Interestingly, an equal amount of participants $(26.3 \%)$ "active readers" reported being "very encouraged" and "barely encouraged" to read, equally. The bulk of responses for "active readers" $(31.6 \%)$ was that they were "fairly encouraged" to read by their parents or guardians. The "active readers" also responded that they were "not encouraged at all" and "somewhat encouraged" at 5.3\% and $10.5 \%$, respectively. These two variables have a p-value of 0.153 and $p>.05$. If $55.6 \%$ of self-identified "not active readers" said they were barely encouraged to read by their parents and 26.3\% or "active readers" said they were very encouraged to read, then it is easy to draw a logical conclusion that parental encouragement impacts whether someone will turn out to be an active reader or not, although the statistical evidence says otherwise.

\begin{tabular}{|c|c|c|c|}
\hline \multicolumn{4}{|c|}{ Chi-Square Tests } \\
\hline & Value & df & $\begin{array}{c}\text { Asymptotic } \\
\text { Significance } \\
\text { (2-sided) }\end{array}$ \\
\hline \begin{tabular}{|l|} 
Pearson Chi-Square \\
\end{tabular} & $21.697^{\mathrm{a}}$ & 16 & .153 \\
\hline Likelihood Ratio & 22.998 & 16 & .114 \\
\hline $\begin{array}{l}\text { Linear-by-Linear } \\
\text { Association }\end{array}$ & 4.145 & 1 & .042 \\
\hline $\mathrm{N}$ of Valid Cases & 198 & & \\
\hline
\end{tabular}

More than half of "not active" readers, 55.6\%, stated that they were "barely encouraged to read" by their siblings. This is what stands out in that category as the other four values are have a less than 5\% difference in value. In contrast, the 
"active readers", mostly (36.8\%) feel that they were "fairly encouraged" to read by their siblings. In addition, the same amount of respondents $(15.8 \%)$ reported to being both "barely encouraged" and "very encouraged" to read by their siblings in this particular sample of participants. These two variables have a p-value of 0.115



In relation to external encouragement in the community the values assigned are the same as the parent / sibling encouragement. Both "active" and "not active" readers responded that they feel "somewhat encouraged" to read through community activities. The response was a majority of $40.7 \%$ of "not active readers" and $31.6 \%$ of "active readers. The majority of "active readers" said that they feel "barely encouraged" to read by their communities. It should be mentioned that these variables have a p-value of 0.115 .

\begin{tabular}{|c|c|c|c|}
\hline \multicolumn{4}{|c|}{ Chi-Square Tests } \\
\hline & Value & df & $\begin{array}{c}\text { Asymptotic } \\
\text { Significance } \\
\text { (2-sided) }\end{array}$ \\
\hline Pearson Chi-Square & $22.956^{\mathrm{a}}$ & 16 & .115 \\
\hline Likelihood Ratio & 21.806 & 16 & .150 \\
\hline $\begin{array}{l}\text { Linear-by-Linear } \\
\text { Association }\end{array}$ & .127 & 1 & .721 \\
\hline $\mathrm{N}$ of Valid Cases & 197 & & \\
\hline
\end{tabular}

\section{DISCUSSION}

The findings show that the overall feeling among citizens and residents in the UAE is that there is a reading culture. The findings also reveal that there is not a statistically significant link between the amount of books in one's home and the likelihood of them becoming an active reader. The key to becoming an active reader is in variety rather than amount. The data also shows that external encouragement from inside the home and the community has an impact on active and not active reading. The study concludes the same as Mansor (2012), that suitability lies in a person's motivation to read.

\section{LIMITATIONS}

This was just a small-scale study done on a pool of 200 participants. Although it is not representative to the general population of the
UAE, it does shed light on some interesting correlations of variables pertaining to active and not active readers. Further research needs to be done on a more representative sample. The data was collected via twitter and this makes it hard to be $100 \%$ accurate in reporting. Plus, this survey was predominantly answered by UAE nationals as opposed to expats and women as opposed to men. These factors need to be taken into consideration and expanded on in future studies. Also, questions should be more spec

\section{REFERENCES}

[1] Akanda, A.K.M., Hoq, K.M.G. and Hasan, N., 2013. Reading Habit of Students in -Social sciences and arts: A case study of Rajshahi University. Chinese Librarianship: an International Electronic Journal, 35, pp.85-99.

[2] Al-Jenaibi, B. (2011). The scope and impact of workplace diversity in the United Arab Emirates-An initial study. Acta Universitatis Danubius. Communicatio, 5(1)

[3] Al-Jenaibi, B. (2014). Comparing the roles of PR practitioners in the public and private sectors in the UAE. International Journal of Information Systems and Social Change (IJISSC), 5(3), 64-76.

[4] Al-Jenaibi, B. (2014). Research practices in public relations organizations in the United Arab Emirates. International Journal of Customer Relationship Marketing and Management (IJCRMM), 5(3), 14-31.

[5] Al Jenaibi, B. (2011). Job Satisfaction: Comparisons among Diverse Public Organizations in the UAE. Management Science and Engineering, 5(2), 53.

[6] Al-Jenaibi, B. (2008). The effects of media campaigns on different cultures. Proceedings of World.

[7] Al-Jenaibi, B. (2015). E-collaboration. public relations and crises management in UAE Organizations. International Journal of ECollaboration, 11(3), 10-28.

[8] Bal, P.M. and Veltkamp, M., 2013. How does fiction reading influence empathy? An experimental investigation on the role of emotional transportation. PloS one, 8(1), p.e55341.

[9] Bower, P., Kontopantelis, E., Sutton, A., Kendrick, T., Richards, D.A., Gilbody, S., Knowles, S., Cuijpers, P., Andersson, G., Christensen, H. and Meyer, B., 2013. Influence of initial severity of depression on effectiveness of low intensity interventions: meta-analysis of individual patient data.

[10] Clark, C. and Rumbold, K., 2006. Reading for Pleasure: A Research Overview. National Literacy Trust. 
[11] Gambrell, L.B., 2015. Getting Students Hooked on the Reading Habit. The Reading Teacher, 69(3), pp.259-263.

[12] Hintikka, J., 1958. On Wittgenstein'sSolipsism'. Mind, 67(265), pp.88-91.

[13] Igwe, K.N., 2011. Reading culture and Nigeria's quest for sustainable development.

[14] Khaleej Times, (2015). Lack of reading reflects in the Arab world: Mohammed. [online] Available at: http://www.khaleejtimes.com/nation/education/l ack-of-reading-reflects-in-the-arab-worldmohammed [Accessed 10 Dec. 2016].

[15] Manguel, A., 2014. A history of reading. Penguin.

[16] Mansor, A.N., Rasul, M.S., Rauf, R.A.A. and Koh, B.L., 2013. Developing and sustaining reading habit among teenagers. The AsiaPacific Education Researcher, 22(4), pp.357365.

[17] Palani, K.K., 2012. Promoting reading habits and creating literate society. Researchers World, 3(2), p.90.
[18] Ruterana, P.C., 2012. The making of a reading society: Developing a culture of reading in Rwanda.

[19] Shihab, I.A., 2011. Reading as critical thinking. Asian Social Science, 7(8), p.209.

[20] Stranger-Johannessen, E., 2014. Promoting a reading culture through a rural community library in Uganda. IFLA journal, 40(2), pp.92101.

[21] Vygotsky, L. S. (1993). The collected works of L. S. Vygotsky. Vol. 2. The fundamentals of defectology (abnormal psychology and learning disabilities). New York: Plenum Press.

[22] Wilson, R.S., Boyle, P.A., Yu, L., Barnes, L.L., Schneider, J.A. and Bennett, D.A., 2013. Lifespan cognitive activity, neuropathologic burden, and cognitive aging. Neurology, 81(4), pp.314321.

Citation: Afra Atiq Juma. "A Look at Readers in the UAE and the Factors that Influence Them." International Journal of Research in Humanities and Social Studies, vol 4 no. 5, 2017, pp. 32-38.

Copyright: (C) Afra Atiq Juma. This is an open-access article distributed under the terms of the Creative Commons Attribution License, which permits unrestricted use, distribution, and reproduction in any medium, provided the original author and source are credited. 